JARMAN, B. (1983) Identification of under privileged areas. British Medical Journal, 286. 1705-1709.

JoHnSON, S., RAMSAY, R., THORNICROFT, G., et al (1998) London's Mental Health. London: King's Fund.

- \& LELUOT, P. (1998) Mental health services in London: evidence from research and routine data. In London's Mental Health (eds S. Johnson. R. Ramsay, G. Thornicroft, et al. pp. 167-192. London: King's Fund.

LELUOTT, P. \& WING, J. (1994) A national audit of new longstay patients. II. Impact on services. British Journal of Psychiatry, 166, 170-179.

Milmis ProJect Group (1995) Monitoring inner London mental lliness services. Psychiatric Bulletin. 19. 276-280.

RirchiE, J., Dick, D. \& Lingham. R. (1994) The Report of the Enquiry into the Care and Treatment of Christopher Clunis. London: HMSO.

SHePHerd, G., BeadsmoOre, A., MoORE, C., et al (1997) Relation between bed use, social deprtvation, and overall bed availability in acute adult psychiatric units, and alternative residential options: a crosssectional survey, one day census data, and stafi interviews. British Medical Joumal, 314, 262-266.

TYRER, P., Evans, K., GANDHI, N., et al (1998) Randomised controlled trial of two models of care for discharged psychlatric patients. British Medical Joumal. 316. 106-109.

WORKING PARTY OF THE SECTION FOR SOCLAL AND COMMUNITY PSYCHIATRY OF THE ROYAL COLlEGE OF PSYCHIATRISTS (1988) Psychiatric Beds and Resources: Factors Influencing Bed Use and Service Planning. London: Gaskell.

Bernard Audini, Research Fellow, Richard Duffett, Former Research Fellow, Paul Lelliott. Director, Alison Pearce, Former Research Assistant, Catherine Ayres, Research Assistant, Royal College of Psychiatrists Research Unit, 11 Grosvenor Crescent, London SWIX 7EE

\title{
Effect of treatment in an active rehabilitation hostel on the need for hospital treatment
}

\author{
Rob Macpherson and Julian Butler
}

\begin{abstract}
Aims and method To describe the work of the 'Vron'. a seven-bed active rehabilltation hostel which has operated in Gloucester for the last 15 years. Such units have been acknowledged as a successful alternative to hospital care for patients with severe mental illness, but nationally are grossly under-provided.

Results Demographic details, admission and discharge data were described for all 103 patients admitted over a 12-year period up to January 1996. Duration of hospital treatment fell from mean 105.8 days one year before and 138.0 days two years before admission to the Vron to: mean 28.6 days one year after and 57.1 days two years after discharge from the Vron. The change was highly significant for both one and two year analyses.

Clinical Implications Residential rehabilitation, provided as part of a comprehensive rehabilitation senvice, was effective at reducing requirement for hospital care. Clinical approaches which contributed to this success were described. The results point to the value of a range of residential hostels, which can through skilled deployment effectively target individual needs for a wide ranging, heterogeneous population.
\end{abstract}

The mental hospital closure programme has been associated with the development of a range of residential community facilities. The rehabilitation hostel, also known as the 'ward in a street', has been recognised in recent reviews (Shepherd. 1991: Young, 1991) and by the Department of Health (1996) as an effective alternative to hospital care for the 'new long-stay' patient. Although such units were generally set up to provide long-term care, studies have consistently shown their success in rehabilitating even the most difficult patients with challenging behaviour, into less dependent settings (see Wykes \& Wing, 1982; Shepherd et al, 1994; Reid \& Garrety, 1996).

In more recent years, descriptions have appeared in the literature of hostels providing more explicitly "fast stream rehabilitation" (Simpson \& Middleton, 1994), or "targeting patients with the greatest chance of rehabilitation" (Shepherd et al, 1994). Such units, adopting a more active rehabilitation approach of deliberately shorter duration, may intervene earlier in the patient's illness history, aiming to 
improve psychosocial function and clinical outcome, and to reduce the requirement for hospital treatment following residential rehabilitation (Hawthorne et al, 1994). Such findings require that residential facilities (and their associated treatment programmes) should be viewed as treatment modalities in their own right, and their effectiveness assessed accordingly.

The present study was an attempt to examine the effectiveness of such a unit over a relatively prolonged period of its operation.

\section{Service context}

The Vron is a seven-bed hostel which opened in 1982. It is a detached Victorian house in a residential area of Gloucester, close to the city and a range of leisure/day care facilities. It is operated by the Mayfield Homes Trust Ltd as a psychiatric nursing home, with 10 full-time equivalent staff provided through the rehabilitation unit in the Severn National Health Service Trust. The unit is not registered to treat patients under the Mental Health Act 1983, and does not have the status of a hospital, but provides 24hour nursed care. A full multi-disciplinary team meets weekly, with senior psychiatric, occupational therapy. social work and psychological input.

The unit was set up to provide short- or medium-term active training in rehabilitation with emphasis on domestic and social skills training. Each patient participates in an individualised programme of cooking and independent living skills, together with education about illness and training in medication management. He or she generally attends sheltered work, training or a day care placement daily through the week. The peer group of residents play an important role through daily team meetings, and the unit can be viewed as a modified therapeutic community. Length of stay has typically been less than 18 months, with discharge of patients into a well developed range of supported accommodation, patients are generally taken on by the associated community rehabilitation team to ensure continuity. It is anticipated that on discharge the skills developed through the residential treatment programme are maintained in the new placement and that the intensive support can gradually be withdrawn leading up to discharge. Four other Mayfield hostels provide longer term care for 28 patients (all having some, albeit slower, throughput), with backup from a 12-bed rehabilitation in-patient unit for readmission/crises. This ward also provides all the continuing in-patient care within the district served by the Trust (population 320000).

\section{The study}

All patients admitted to the Vron between April 1986 and February 1996 were included in the study. The unit was actually opened in April 1984, but health records were not available for the first two years of the unit's operation. There were 103 admissions over this time. Demographic data are shown in Table 1.

Health records were used to determine admission details. In most cases the patients remain under the care of the Gloucester rehabilitation service, and their progress can easily be followed through to the present day. ICD-9 diagnoses (World Health Organization, 1978) were as at the time of Vron admission. In five cases, patients were admitted twice to the Vron. Under such circumstances, admissions were treated as separate episodes and analysed accordingly. However, where Vron readmission took place within the study follow-up time-frame, the readmission was counted as a hospital admission (on the principle that the unit acts as a 'ward' in the community). In practice, this occurred in only one case.

\section{Statistical analysis}

Data were entered in to the SPSS software system for analysis. A non-parametric test, the Wilcoxon matched-pairs signed-ranks test, was used to analyse change in in-patient stay one year and two years before and after treatment in the Vron.

\section{Results}

Demographic, illness-related data and placements pre- and post-Vron admission are presented in Table 1. Mean duration of stay in the Vron was 29.2 weeks (range 0-107 weeks, s.d.=22.5). Length of time in the Vron was significantly negatively correlated with age $(r=-0.21 ; P=0.035)$; patients over 35 years of age spent mean 32.0 weeks, versus mean 25.0 weeks for the under 35-year-olds. The age of patients had decreased since the time of the Vron opening, mean age 36.6 years (range 19-69, s.d. $=15.2$ ) over the first six years, versus mean 33.5 (range 19-58, s.d.=11.0) over the last six years of the study period.

Duration of hospitalisation fell $73 \%$ from mean 105.8 days (range $0-365$, s.d. $=106.5$ ) in the year before Vron treatment to mean 28.6 days (range 0-365, s.d.=75.4) in the year after (Wilcoxon signed-ranks; $Z=6.1, \quad P<0.0001$ ). Hospitalisation fell $58 \%$ from 138.0 days (range $0-730$, s.d. $=160.3$ ) in the two years before Vron treatment to mean 57.1 years (range 0-730, s.d. $=134.9$ ) in the two years after Vron treatment (Wilcoxon signed-ranks; $Z=-5.2$. $P<0.0001$ ). 
Table 1. Demographic/illness-related data and placement pre-and post-Vron treatment

\begin{tabular}{|c|c|}
\hline & $n(\%)$ \\
\hline \multicolumn{2}{|l|}{ Gender } \\
\hline $\begin{array}{l}\text { Male } \\
\text { Female }\end{array}$ & $\begin{array}{l}67(65) \\
36(35)\end{array}$ \\
\hline Mean age on admission to the Vron & $\begin{array}{l}35.1 \text { (range } \\
19-69, \text { s.d. }=13.2 \text { ) }\end{array}$ \\
\hline \multicolumn{2}{|l|}{ Primary ICD-9 diagnosis } \\
\hline Schizophrenia/schizoaffective & $71(68.9)$ \\
\hline Affective & $13(12.6)$ \\
\hline Personality disorder & $8(7.8)$ \\
\hline Obsessive-compulsive disorder & $5(4.9)$ \\
\hline Other & \\
\hline Organic & $2(1.9)$ \\
\hline Leaming difficulties & $2(1.9)$ \\
\hline Substance abuse & 1 (1.0) \\
\hline Anxiety neurosis & $1(1.0)$ \\
\hline \multicolumn{2}{|l|}{ Placement prior to Vron admission } \\
\hline Acute ward & $59(57.3)$ \\
\hline $\begin{array}{l}\text { Independent/family } \\
\text { accommodation }\end{array}$ & $7(6.8)$ \\
\hline Supported lodgings & $22(21.4)$ \\
\hline Group home & $7(6.8)$ \\
\hline $\begin{array}{l}\text { Other (hostel, 3; no fixed abode, 2; } \\
\text { residential home, 2; private } \\
\text { hospltal, 1) }\end{array}$ & $8(7.8)$ \\
\hline \multicolumn{2}{|l|}{ Placement following Vron admission } \\
\hline Supported lodgings & $41(39.8)$ \\
\hline $\begin{array}{l}\text { Independent/family } \\
\text { accommodation }\end{array}$ & $19(18.4)$ \\
\hline Group home & $18(17.5)$ \\
\hline Hospltal & $8(7.8)$ \\
\hline Private/residential care & $7(6.8)$ \\
\hline Long-term hostel & $7(6.8)$ \\
\hline Bed and breakfast & $2(1.9)$ \\
\hline No fixed abode & $1(1.0)$ \\
\hline
\end{tabular}

\section{Discussion}

Our impression was that the unit adapted over the 12-year period studied, initially treating more elderly, institutionalised 'old' long-stay patients who had spent many years in institutions, but shifting its focus (with the closure of the longstay wards) to a younger, more heterogeneous patient group, admitted at an earlier stage of illness. The data showed that in the most recent seven years, six patients with personality disorder and five patients with 'other' diagnoses (two with learning disability, one substance misuse, one anxiety neurosis and one with an organic disorder) were admitted, as opposed to two personality disordered and one 'other' diagnosed patient in previous years. Most patients were admitted to the Vron from acute wards, with a significant proportion coming directly from community placements such as supported lodgings, which were breaking down. As a 24hour nursed facility, it has in some cases acted as an alternative to acute hospital treatment. Over the study period pressure on the acute wards has increased, the Vron acting to reduce this pressure and to provide a more therapeutic setting for patients needing intensive support over the medium-term, and an active rehabilitation programme to rebuild skdlls.

The results of this study show a marked, highly significant change in duration of hospital treatment between the year and two years before and after admission to the Vron. Although this was consistent with our impression that the unit was effectively preventing new long-stay patients and blocking 'revolving door' admissions, some caution is needed in interpretation of these findings: This was not a controlled study, and the effectiveness of 'standard' hospital treatment cannot be directly compared. There was no recording of clinical change through the period of Vron treatment (although rating of this is now in place), and actual health/social gains were not measured. Due to the lack of a control group, it is not possible to rule out the possibility that the reduction in admissions may be due to the natural progression of illness. Similarly, it is possible (as most patients were discharged to supported accommodation) that the longer term support after discharge is what prevented further hospitalisation, rather than the impact of the Vron treatment programme.

However, the change in requirement for hospital care was considerable, and was in keeping with a finding in the only similar previous study found in the literature: Hawthorne et al (1994) found that 104 patients treated in two hostels in San Diego had significantly fewer admissions and shorter hospital stay in the year after (versus the year before) residential care. In the American study, the researchers also demonstrated significantly less psychopathology in patients, following hostel rehabilitation, and concluded that psychosocial residential treatment could offer "cost-effective and clinically efficacious care to persistently mentally 111 patients". These authors concluded that projected savings in hospital costs alone exceeded the annual costs of hostel facilities. Lelliott (1996) showed that in the UK there are now only one-third of residential places for patients with severe mental illness as compared with 40 years ago. The NHS Executtve has recommended that health authorities should commission a further 5000 24-hour nursed beds nationally (NHS Executtve, 1994), and our findings add further support to the potentlal value of such units.

The experience of staff working in the Vron suggests that a number of factors may be important to the success of such units: Engagement in a therapeutic programme is crucial and needs to be established well before admission, usually by a programme of gradually increasing 
visits. Family work is generally necessary, including at times the employment of contracts to manage boundary issues in over-involved families. Regular input from outside agencies for staff and patients, through the course of admission, is encouraged. Training and staff support are important. Strong links with the supported accommodation officer and the community rehabilitation team have proved helpful in finding appropriate placement and ongoing support after residential rehabilitation.

\section{Acknowledgements}

We thank the Barnwood Trust, which contributed to the cost of data analysis; Heather Priestley for her help with data collection; and Julie Bundy for her work on producing the manuscript.

\section{References}

DEPARTMENT OF HEALTH (1996) Residential Needs for Severely Disabled Psychiatric Pattents: The Case for Hospital Hostels. London: Department of Health

HAWTHORNE, W. B., FALS-STEWARD, W. \& COHR, J. B. (1994) A treatment outcome study of community-based residential care. Hospital and Community Psychiatry. 46. 152-155.

LELUOTT, P. (1996) Meeting the accommodation needs of the most severely mentally ill. Joumal of Interprofessional Care, 10, 241-247.
NHS EXrcuTIVE (1994) 24-Hour Nursed Care for People with Severe and Enduring Mental Illness. Leeds: NHS Executtve.

REID, Y. \& GARRETY, P. (1996) A hostel-ward for new long stay patients: Sixteen years progress. Journal of Mental Health, 5, 77-89.

SHEPHERD, G. (1991) Psychiatric rehabilitation for the 1990s. In Theory and Practice of Psychlatic Rehabilitation (eds F. N. Watts \& D. H. Bennett). Chichester: Wiley.

-. KInG, C. \& Fowher, D. (1994) Outcomes in hospice hostels. Psychiatric Bulletin, 18, 609-612.

SiMPSON, S. \& MiDDLETON, N. (1994) Fast stream psychlatric rehabilitation after recent hospital closure. Psychiatric Bulletin, 18, 613-614.

WORLd HEALTh ORGanization (1978) Mental Disorders: Glossary and Guide to thetr Classification in Accordance with the Ninth Revision of the International Classification of Diseases (ICD-9). Geneva: WHO.

WYKEs, T. \& WING. J. K. (1982) "New" long-stay patients: An evaluative study of a "ward in a house". Monograph Supplement 2, Psychological Medicine. Cambridge: Cambridge University Press.

Young, R. (1991) Residential Needs of Severely Disabled Psychlatric Patients - the Case for Hospital Hostels. London: HMSO.

*Rob Macpherson, Consultant in Rehabilitation/ General Psychiatry, Wotton Lawn, Horton Road, Gloucester GL1 3LW; and Julian Butler, Registered Mental Nurse and Manager, The Vron Rehabilitation Hostel, Gloucester

*Correspondence

\title{
Electroconvulsive therapy in Wales
}

\author{
Richard Duffett, Drew Ridley Siegert and Paul Lelliott
}

\begin{abstract}
Aims and mothod The use of electroconvulsive therapy (ECI) was surveyed over the first six months of 1996 in Wales. Data on the indications for ECT and clinical outcome were collected in the first three months.

Results The computed annual rate was 22 patients treated with ECT per 100000 population. Women constituted $71 \%$ of those recelving ECT (236/321). Elghty-three per cent had an affective disorder, and $80 \%$ had falled to respond to previous treatments. Only $33 \%$ of patients had been prescribed more than one class of antidepressant, and only $25 \%$ had recelved augmentation with lithium or an alternative drug before being given ECT.

Clinical implications ECT is mostly used after a fallure of patients to respond adequately to a course of antidepressants.
\end{abstract}

Between 1990 and 1993 (data were last collected in Wales in 1993), the number of patients reported to be receiving electroconvulstve therapy (ECT) in Wales fell from by 26\% from 39 to 29 per 100000 population (Welsh Office, 1994). A number of factors may account for this:

(a) Improvements in pharmacotherapy with the introduction of effective antidepressants with fewer side-effects and the increased use of lithium as an adjunct. The treatment of resistant depression has probably also become more systematic with the introduction of treatment protocols.

(b) Stigma and adverse publicity may have made patients more reluctant to accept 